\title{
Seasonality in the Indian Stock Markets: A Study of Calendar Effects
}

\author{
Harish Kumar* and Mridul Dawar**
}

\begin{abstract}
Theoretical and technological advances in Behavioural Finance over the last decades seem to have shifted the paradigm away from the Efficient Market Hypothesis proposed by Fama in 1970s. The hypothesis implied that securities are always priced efficiently since all the relevant information is fully reflected in their prices. However, this normative statement comes under heavy scrutiny with the existence of seasonality in stock returns. This paper investigates seasonality in the Indian stock markets through the existence of calendar effects. Employing time series analysis on data from January 1999 to December 2015, the presence of calendar effects is studied in three BSE indicesSensex, BSE200 and BSE 500 using a dummy variable regression model in both the daily returns (using EGARCH modelling process) and monthly returns (using OLS estimation procedure). It is found that the while the SENSEX index does not show any significant calendar effect, seasonality does manifest in the larger BSE 200 and BSE 500 indices in form of both days-of-the-week effect and month-of-the-year effect, thereby suggesting that Indian stock markets do not show informational efficiency even in the weak form. The study concludes that the observed patterns are useful in timing the deals by exploiting the observed irregularities in the Indian stock market returns.
\end{abstract}

Keywords: Efficient Market Hypothesis; Seasonality; Calendar effects; Market efficiency; Indian stock markets.

\subsection{Introduction}

Since its formulation by Fama (1970), the efficient market hypothesis has been a cornerstone of modern finance. Essentially, the idea of informational efficiency in capital markets advocates the futility of the trading strategy based on information.

*Corresponding author; Assistant Professor, Shri Ram College of Commerce, University of Delhi, Delhi, India. (Email id: harishkumardse@gmail.com)

**Student, Shri Ram College of Commerce, University of Delhi, Delhi, India.

(Email id: mriduldawar@gmail.com) 
The EMH postulates that in an efficient market, information is very quickly spread amongst the market participants and as such, no one individual can earn excess returns on the basis of such common information. The informational efficiency of the market can be divided into three forms based on the type of information:

(i) Weak form of efficiency: implies that the stock prices reflect all past information in the market. As such, the analysis of past information is irrelevant in prediction of future price movements.

(ii) Semi-strong form of market efficiency: states that all publicly available information are reflected in the stock prices. Here, the prices reflect both past information and currently prevalent information i.e. it relates to the idea that the stock prices instantaneously adjust to the news arriving in the market in addition to the past information.

(iii) Strong form of market efficiency: is the broadest form comprising of both the weak and semi-strong forms. It implies that all information, whether public or private information, is reflected in the stock prices.

However, the idea of market efficiency is violated in the existence of seasonality. Seasonality is defined as the regular and repetitive fluctuation in a time series occurring periodically in a period of less than a year. Seasonality has been attributed to a number of factors such as climate, customs and traditions and time preference for goods. For example, sales of cotton clothes show a significant increase in summer season over winter season. A review of literature on the past hundred years shows that stock returns, like other economic commodities exhibit systematic patterns at certain times of the year in form on specific days, weeks or months. The existence of seasonality impinges the weak form of market efficiency, as past patterns with respect to time make the stock prices predictive rather than random. The seasonality in the stock gives rise to calendar anomalies i.e. the stock prices being systematically lower or higher in a particular calendar period. For example, in a 'weekend effect', the returns of a stock are systematically higher on Friday and lower on Monday.

Calendar effects imply that at a particular day, month or period of the year stock returns behave in contradiction to the market efficiency hypothesis. As such, the seasonality is reflected in the varying distribution of stock returns within the period of study with such variation presenting a systematic pattern. Hence, the existence of calendar effects can entail emergence of predictable patterns in returns exploitable by investors to earn above normal returns. Some calendar effects can be described as:

- Day-of-the-week effect: The day-of-the-week effect relates to the significant inequality in mean of returns for different days of the week. 
- Month-of-the-year effect: This calendar effect relates to the significant inequalities in the mean of returns for different months of the year, i.e. a particular month generates a significantly different (higher or lower) return than the other remaining months in the year.

- Weekend effect: The observation that mean returns on Monday are the smallest and sometimes even negative, while mean returns on Friday are positive and highest compared to returns on other days of the week is known as the weekend effect.

\subsection{Review of Literature}

The notion of efficiency in capital markets has been repeatedly scrutinised to check for seasonality in the returns of stock markets. The level of market efficiency i.e. the degree to which stock prices and other securities' prices reflect all available and relevant information is not constant through capital markets of different countries. Wachtel (1942) is credited as being the first to document calendar effects. He examined the Dow Jones Industrial Average and observed the January effect- a seasonal anomaly where the mean return observed in January was greater than that in any other month. Rozeff and Kinney (1976) and Reinganum (1983) reached conclusions similar to the one drawn by Wachtel. Gultekin and Gultekin (1983) employ both parametric and nonparametric tests to study the returns of stock markets of sixteen industrial countries with the January effect found to significant in 15 of those 16 countries. The most common explanation for the January effect is that individual investors, who are sensitive to income tax rates, sell stocks for tax reasons at year end (to claim a capital loss), thereby depressing the prices of securities. Also known as the tax-loss selling hypothesis, it claims that prices rebound in January due to reinvestment. Brown et al. (1985) have reported December-January effect in the Australian Stock Market. They ascribe a JulyAugust effect to the financial year in Australia (July to June).

Studies have also documented evidence of the day of the week effect in stock market returns. Cross (1973) studied the weekend effect in several US market indexes and found that the mean returns of the S\&P 500 for the period 1953 to 1970 on Friday was higher than the mean return on Monday. French (1980), the first to use statistical testing and mathematical modelling to test calendar effects, reports significantly negative average returns on the stock markets on Mondays. He studied the S\&P 500 Index over the period 1953 through 1977 and suggested that the possible explanation of the weekday effect was a tendency for firms to delay the announcement of bad news until the weekend to avoid market disruption. Jaffe and Westerfield (1985) used the SLR model and conducted t-tests and F-tests to study day-of-the-week effects by studying the 
4 | MUDRA: Journal of Finance and Accounting, Volume 4, Issue 1, Jan-Jun 2017

stock markets of the United Kingdom, Japan, Canada and Australia. They found that the lowest returns occurred, in Canada and in the UK, on Monday. In Japanese and Australian markets, the lowest returns were observed to occur on Tuesday. The results obtained were statistically significant. However, Borges (2009) endorsed single variable dummy regression analysis using GARCH and bootstrapping techniques in addition to the standard OLS procedures to test for seasonalities in stock market returns.

In the Indian context, several studies have been conducted to check the presence of calendar effects. Broca (1992) examined the daily returns during the period 19841989 of the BSE National Index. He observed that the lowest mean return occurred on Wednesday instead of Monday. Using the Kruskall-Wallis test in his analysis, he provided the first conclusive corroboration of the presence of day-of-the-week effects in Indian markets. Kaur (2004) examined two Indian indices (BSE Sensex and S \& P CNX Nifty) and two American indices (S\&P 500 and NASDAQ) to test for day-of-the-week and month-of-the-year effects and observed significant lower returns in March and September and significant positive returns in February and December. The study found a positive Wednesday effect and concluded that the response to news arrival was asymmetrical. Sarma (2004) used a non parametric Kruskall-Wallis Test to check for the presence of Seasonality in the Indian Stock Market returns during the post liberalisation period. The study examined SENSEX, NATEX, and BSE200 and concluded that the Monday-Friday set had the highest positive deviation.

Yakob, Beal and Delpachitra (2005) used regression analysis to study returns of the stock market of India and nine other countries in the Asia Pacific region, namely, Australia, China, Hong Kong, Japan, Indonesia, Malaysia, Singapore, South Korea and Taiwan for the period Jan 2000 to March 2005. Statistically significant positive results were found in May, November and December and statistically significant negative results were found in March and April. Sah (2008) used GARCH modelling to study seasonality in the returns of Nifty and Nifty Junior. He observed, over the study period of January 2005 to December 2008, a Friday effect and month-of-the-year effects for the returns in July, September, December and January. Patel (2008) identified two month-ofthe-year effects, namely the November-December effect and a March to May effect, wherein the mean returns in these months were higher and lower respectively than the other months. Patel \& Radadia (2012) concluded that a significant Monday effect was present in the stock market returns of India, China, Japan and Hong Kong. Recently, Purohit and Tyagi (2015), through their analysis of stock market returns for the period 1995 to 2013, have concluded that a "December effect" exists in the Indian stock market returns. This effect, according to them, can be ascribed to robust economic activity during December due to festivals. 


\subsection{Research Design}

For the alienation of the day-of-the-week effects, the daily closing values of the Sensex, BSE 200 and BSE 500 for the period January $1^{\text {st }} 1999$ to $31^{\text {st }}$ December 2015 were downloaded from the website of the Bombay Stock Exchange. A total of 4236 observations for both Sensex and BSE 200 and 4217 observations for BSE 500 have been analysed over the study period. This data, organized according to day-of-the-week (Monday to Friday), has been used to investigate the equality of mean returns of the day. To study the month-of-the year effects, the information about the opening and closing values of these indices for each month in the period under consideration was downloaded from the BSE website. The downloaded data, containing information about 204 months, was then examined to test the equality of mean returns of the months under consideration. Data points, covering a 17 -years period, for multiple indices have been analyzed to improve the accuracy and reliability of the results obtained.

The returns have been calculated as follows:

$r_{t}=\ln \left(P_{t} / P_{t-1}\right)$

where $r_{t}$ is the $\log$ return of the stock market index and $P_{t}$ is the stock index at date $t$. The $\log$ returns are continuous rates of returns, computed as the log of the ratio of the price (daily or monthly) of the current period's price (daily or monthly) to the previous period.

SENSEX is a free-float market-weighted stock market index of 30 wellestablished and financially sound companies listed on Bombay Stock Exchange that are representative of thirteen industrial sectors of the Indian economy. The level of the index shows the total market value of all the stocks in the index relative to a particular base period. The base value of the index is taken as 100 on April 1, 1979. BSE 200 and BSE 500 are also free-float market-weighted stock market indices of 200 and 500 companies respectively, listed on Bombay Stock Exchange. The greater number of companies in these indices ensures that market trends are reflected in a more effective manner and provides a better representation to the increased number of equity stocks, market capitalization and new industry groups. The base value of BSE 200 is 100 and 1989-90 is the base year. The base value of BSE 500 is taken as 1000 on $1^{\text {st }}$ February, 1999.

A common problem with the time series data analysis technique is that the regression results may be spurious if the data series is non-stationary. The study employs Augmented -Dickey Fuller Test and Phillip Peron test as the unit-root test to check for stationarity. The existence of a unit root indicates that the data is non-stationary. Further, findings by Connolly $(1989,1991)$ document several specific problems on account of standard OLS estimation procedures in time series analysis not accounting the timedependent changes in volatility in financial market returns. These include (i) 
6 | MUDRA: Journal of Finance and Accounting, Volume 4, Issue 1, Jan-Jun 2017

autocorrelation of the stock market index returns; (ii) non-normality of the residuals and; (iii) the variance of the residuals may not be constant. As such, it is important to check for heteroskedasticity in the residuals to account for time varying volatility normally seen in stock return series. Accordingly, the ARCH LM test is employed and the results are interpreted at 5\% level of significance with the null hypothesis that no ARCH effect exists in the log return series.

\subsection{Model specification}

To study the presence of seasonality in the daily and monthly patterns in the stock returns of BSE Sensex, BSE 200 and BSE 500, a Dummy Variable Regression model is employed. The technique allows quantification of qualitative aspects as explanatory variables in a regression model. A dummy variable (alternatively called binary, categorical or indicator variable) is a variable which takes either of the two alternative values of 1 or 0 , with 1 indicating the presence of an attribute and 0 indicating its absence.

A common approach in research using stock market returns uses a dummy regression model, where for q categories of variables, (q-1) dummies will be needed with explicit omission of one category. The estimated intercept for the corresponding equation represents the intercept for the omitted category while its coefficients represent the intercepts for other categories. Under this approach, the regression model can be specified as:

$r_{t}=\alpha+\beta_{2} * D_{2 t}+\beta_{3} * D_{3 t}+\beta_{4} * D_{4 t}+\beta_{5} * D_{5 t}+\mu_{t}$

where $r_{t}$ represents the returns of the stock market index, $D_{i t}$ are dummy variables that take on the value of 1 if the corresponding return for day $t$ is a Tuesday, Wednesday, Thursday or Friday, respectively and 0 otherwise. Since the dummy for Monday is missing, the constant $\alpha$ reflects the mean return on Mondays; $\beta^{*}$ are coefficients representing the mean excess daily returns on the remaining days of the week, relative to Mondays and $\varepsilon_{\mathrm{t}}$ is the error term.

However, the above model gives the best specification if an a priori belief is held that the calendar effect exists on one particular day. But, where there is no previous expectation whether a particular calendar effect exists or not on a particular day, then the model is not appropriate enough. To avoid the dummy variable trap, an alternative specification includes the dummy variables for all the weekdays (all five of them) while excluding the intercept, given as:

$r_{t}=\beta_{1} D_{1 t}+\beta_{2} D_{2} t++\beta_{3} D_{3 t}+\beta_{4} D_{4 t}+\beta_{5} D_{5 t}+\mu_{t}$ 
In light of the above, to examine the days of the week effect in the three indices, the dummy variable regression model is specified as follows:

$R_{t}=\beta_{1}$ Monday $+\beta_{2}$ Tuesday $+\beta_{3}$ Wednesday $+\beta_{4}$ Thursday $+\beta_{5}$ Friday $+\mu_{t}$

To study the month-of-the-year effect in the monthly return series of the indices, the model is specified as:

$R_{t}=\beta_{1}\left(\mathrm{~d}_{\mathrm{Jan}}\right)+\beta_{2}\left(\mathrm{~d}_{\mathrm{Feb}}\right)+\beta_{3}\left(\mathrm{~d}_{\text {Mar }}\right)+\beta_{4}\left(\mathrm{~d}_{\mathrm{Apr}}\right)+\beta_{5}\left(\mathrm{~d}_{\text {May }}\right)+\beta_{6}\left(\mathrm{~d}_{\text {Jun }}\right)+\beta_{7}\left(\mathrm{~d}_{\text {July }}\right)+\beta_{8}\left(\mathrm{~d}_{\text {Aug }}\right)+$ $\beta_{9}\left(\mathrm{~d}_{\text {Sept }}\right)+\beta_{10}\left(\mathrm{~d}_{\text {Oct }}\right)+\beta_{11}\left(\mathrm{~d}_{\text {Nov }}\right)+\beta_{12}\left(\mathrm{~d}_{\text {Dec }}\right)+\mu_{t}$

\subsection{Hypothesis}

For testing the days-of-the-week effect, the null hypothesis states that returns across all days are equal i.e.

$\mathbf{H}_{\mathbf{0}}: \beta_{0}=\beta_{1}=\beta_{2}=\beta_{3}=\beta_{4}$

$\mathbf{H}_{1}$ : At least one $\beta$ is different

For testing the weekend effect, our hypothesis is

$\mathbf{H}_{\mathbf{0}}: \beta_{0}=0$

$\mathbf{H}_{1}: \beta_{0}$ is not equal to zero

For testing the month-of-the-year effect, the hypothesis is framed as:

$\mathbf{H}_{\mathbf{0}}: \beta_{0}=\beta_{1}=\beta_{2}=\beta_{3}=\beta_{4}=\beta_{5}=\beta_{6}=\beta_{7}=\beta_{8}=\beta_{9}=\beta_{10}=\beta_{11}$

$\mathbf{H}_{1}$ : At least one $\beta$ is different

\subsection{Empirical Analysis}

Prior to the formal analysis of the descriptive statistics for the log returns of the BSE SENSEX, BSE 200 and BSE 500 indices, the time series plots for the closing index values and log returns series reveal the ebb and flow over time. This can be seen in Figure 1 presenting the time series of the closing values of the three indices on the BSE. It can be seen that prices on the index move slowly at certain points in time and faster at others. This can be attributed to effects of the news and information disseminated within that specific time period with positive news causing prices to grow and vice versa. From this graph, the price growth before the global financial crisis in 2008 and drop in the closing prices during the crisis (2008-2009) is eminently visible.

Figure 2 presents the time series for logarithmic daily and monthly returns of the SENSEX, BSE 200 and BSE 500 indices. The series exhibit high volatility during 20082009 attributable to the global financial crises in the said period. Prima facie, from an examination of these graphs, it appears that these disturbances follow a mean reverting 
process and are heteroskedastic with non-constant variance. Further, periods of high and low volatility, when returns are more and less dispersed respectively, could indicate presence of volatility clustering in series. As such, these are tested through formal statistical procedures.

Figure 1: Time series of closing values on the BSE indices

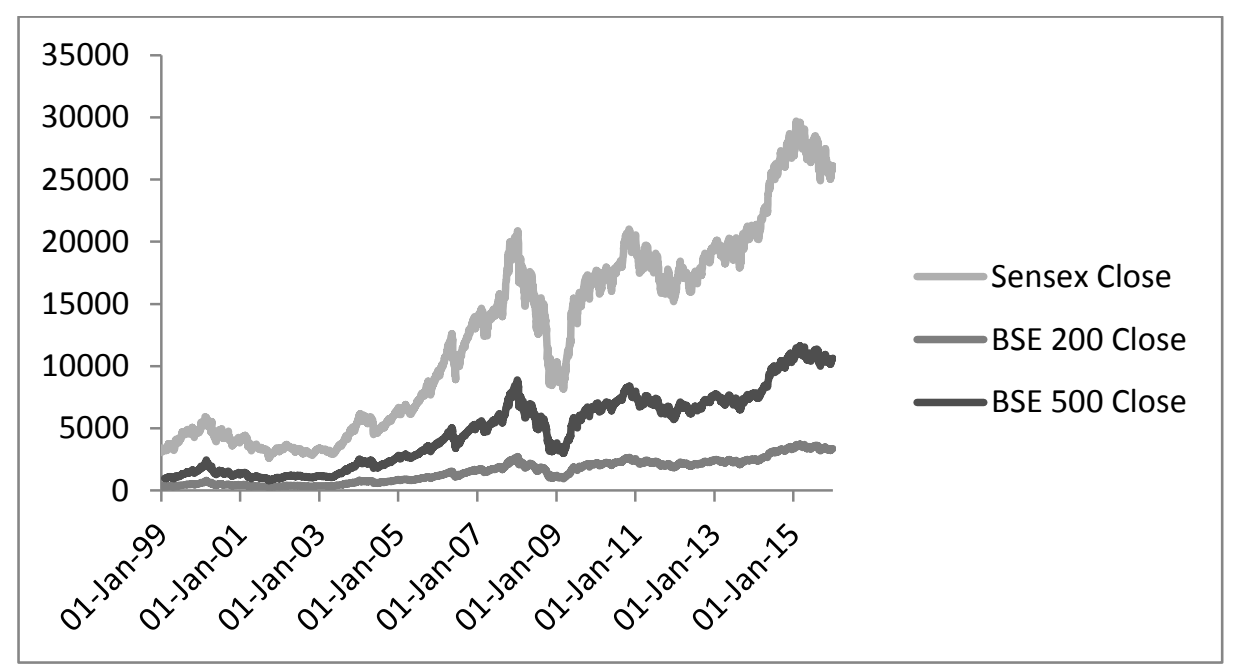

Source: Author's calculation based on BSE website

Table 1 computes the descriptive statistics for the three indices. As seen, all the three indices show positive returns over the study period with BSE 200 and BSE 500 providing higher identical returns. It can be also seen that the skewness and kurtosis of the three indices deviate from the normal distribution where skewness is equal to 0 and kurtosis equals 3. Statistically, skewness measures the asymmetry of the distribution around its mean while kurtosis indicates the height of the distribution. Here, the three indices show negative skewness which indicates that their distributions are skewed to the left i.e. there is a overspread towards negative values. For data representing financial returns, it reflects the significant probability of small gains and a small probability of large losses in terms of obtaining large negative returns. Further, the kurtosis value for all three indices is greater than 3 . It shows positive excess kurtosis showing that the distributions are peaked and are leptokurtic in nature i.e. fat-tailed in comparison to the normal distribution. The p-values of the Jarque-Bera normality test confirm the nonnormality of the data at $5 \%$ level of significance and allow the rejection of the null hypothesis that the returns follow a normal distribution. 
Seasonality in the Indian Stock Markets: A Study of Calendar Effects | 9

Figure 2: Time Series Plot of Log Returns on the BSE Indices

BSE Sensex Daily Returns (1999-2015)



Returns Sensex

BSE 200 Daily Returns (1999-2015)

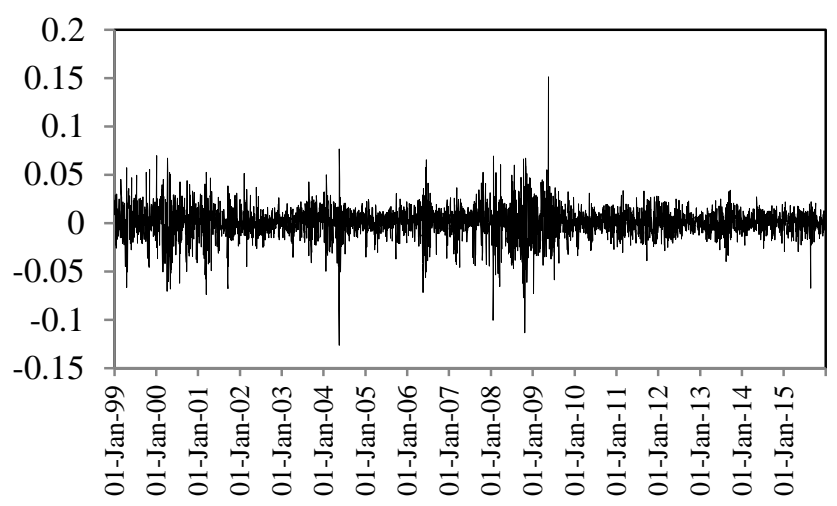

Returns BSE 200

BSE 500 Daily Returns (1999-2015)

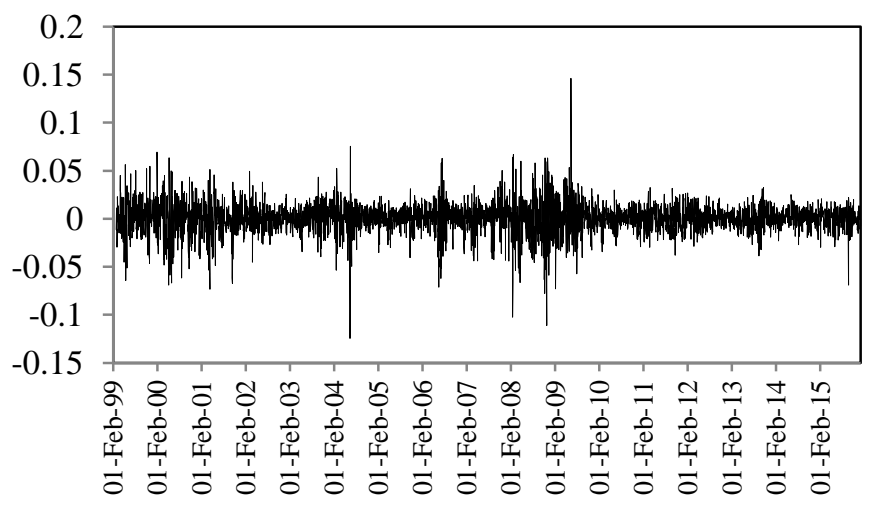

— Returns BSE 500 
10 | MUDRA: Journal of Finance and Accounting, Volume 4, Issue 1, Jan-Jun 2017

Figure 2: Time Series Plot of Log Returns on the BSE Indices

BSE Sensex Monthly returns (1999-2015)

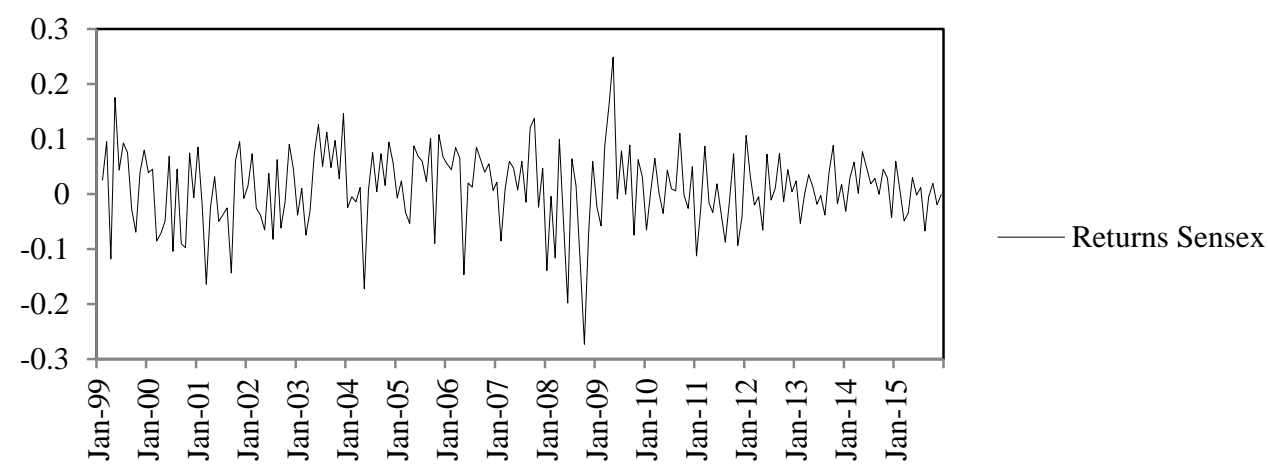

BSE 200 Monthly Returns (1999-2015)

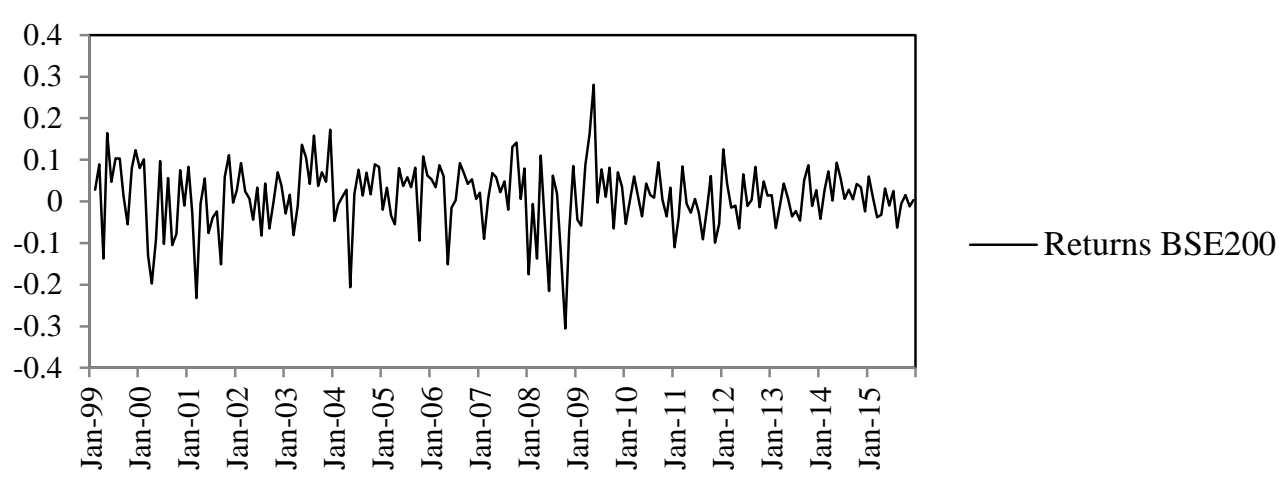

BSE 500 Monthly returns (1999-2015)

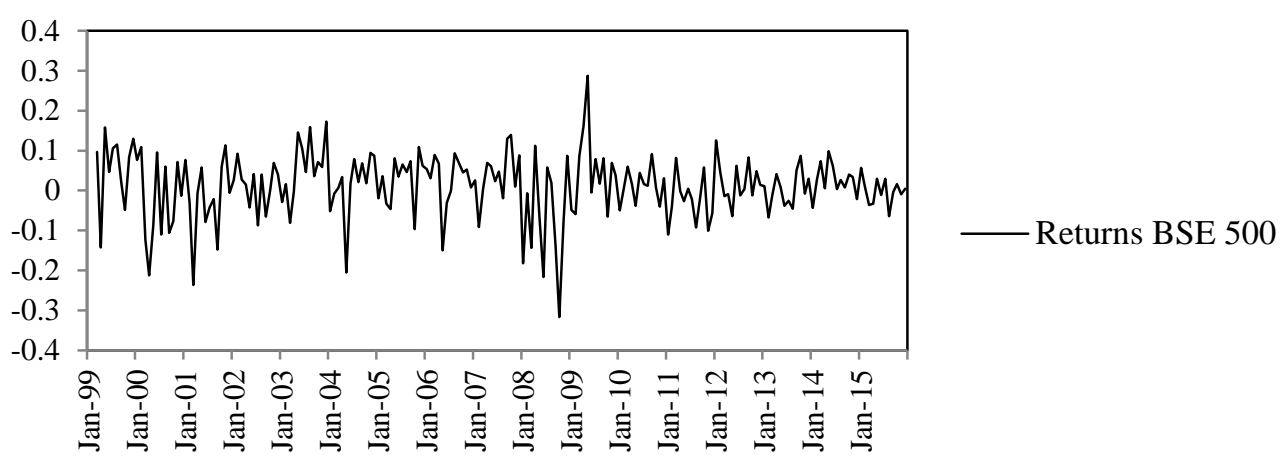


Table 1: Descriptive Statistics of returns on Sensex, BSE 200 and BSE 500

\begin{tabular}{|c|c|c|c|}
\hline & BSE Sensex & BSE 200 & BSE 500 \\
\hline Mean & 0.000506 & 0.000561 & 0.000561 \\
\hline Median & 0.00105 & 0.001435 & 0.001623 \\
\hline Maximum & 0.1599 & 0.151082 & 0.146179 \\
\hline Minimum & -0.118092 & -0.126364 & -0.124398 \\
\hline Std. Dev. & 0.015698 & 0.015825 & 0.015633 \\
\hline C.V. & 31.02371542 & 28.20855615 & 27.86631016 \\
\hline Skewness & -0.149282 & -0.42594 & -0.49127 \\
\hline Kurtosis & 9.506324 & 9.497331 & 9.449259 \\
\hline Jarque-Bera & 7485.608 & 7577.3 & 7476.079 \\
\hline P-Value & 0 & 0 & 0 \\
\hline Observations & 4235 & 4235 & 4216 \\
\hline
\end{tabular}

The stationarity of the underlying data is tested by the Augmented Dickey Fuller Test and Phillip-Perron Test with the null hypothesis that the data is not stationary i.e a unit root exists. Table 2 displays the the results of ADF and PP test. The t-statistics and the corresponding p-values of both the test in Table 2 permit rejection of the null hypothesis, indicating the stationarity of the returns.

Table 2: Results of the Unit Root Test

\begin{tabular}{|c|c|c|c|}
\hline & & t-statistics & p-value \\
\hline \multirow{3}{*}{$\begin{array}{l}\text { Augmented Dickey-Fuller test } \\
\text { statistic }\end{array}$} & SENSEX & -60.90457 & 0.0001 \\
\hline & BSE 200 & -57.81507 & 0.0001 \\
\hline & BSE 500 & -58.66357 & 0.0001 \\
\hline \multirow{3}{*}{ Test critical values: } & $1 \%$ level & -3.43171 & \\
\hline & $5 \%$ level & -2.862026 & \\
\hline & $10 \%$ level & -2.567072 & \\
\hline & & t-statistics & p-value \\
\hline \multirow{3}{*}{ Phillips-Perron test statistic } & SENSEX & -60.79957 & 0.0001 \\
\hline & BSE 200 & -58.90773 & 0.0001 \\
\hline & BSE 500 & -58.25171 & 0.0001 \\
\hline \multirow{3}{*}{ Test critical values: } & $1 \%$ level & -3.43171 & \\
\hline & $5 \%$ level & -2.862026 & \\
\hline & $10 \%$ level & -2.567072 & \\
\hline
\end{tabular}


12 | MUDRA: Journal of Finance and Accounting, Volume 4, Issue 1, Jan-Jun 2017

Next, the model (3) is estimated to study the days of the week effects in daily returns of the three indices. The OLS estimation results are shown in Table 3.

Table 3: Results of OLS estimation procedure on Daily returns of three indices

\begin{tabular}{|l|c|c|c|c|}
\hline & \multicolumn{5}{|c|}{ BSE Sensex } \\
\hline \multicolumn{1}{|c|}{ Days } & Coefficient & Std. Error & t-Statistic & Prob \\
\hline Monday & 0.000544 & 0.000539 & 1.008429 & 0.3133 \\
\hline Tuesday & 0.000353 & 0.00054 & 0.653773 & 0.5133 \\
\hline Wednesday & 0.001093 & 0.00054 & 2.02301 & $\mathbf{0 . 0 4 3 1}$ \\
\hline Thursday & 0.000301 & 0.000541 & 0.556686 & 0.5778 \\
\hline Friday & 0.00018 & 0.000545 & 0.330698 & 0.7409 \\
\hline \multicolumn{5}{|c|}{ BSE 200 } \\
\hline Days & Coefficient & Std. Error & t-Statistic & Prob \\
\hline Monday & 0.000908 & 0.000543 & 1.671281 & 0.0947 \\
\hline Tuesday & 0.000342 & 0.000544 & 0.629627 & 0.529 \\
\hline Wednesday & 0.001233 & 0.000544 & 2.264505 & $\mathbf{0 . 0 2 3 6}$ \\
\hline Thursday & 0.000131 & 0.000545 & 0.239496 & 0.8107 \\
\hline Friday & $8.38 \mathrm{E}-05$ & 0.00055 & 0.152401 & 0.8789 \\
\hline \multicolumn{1}{|c|}{} & \multicolumn{2}{|c|}{ BSE 500 } \\
\hline Days & Coefficient & Std. Error & t-Statistic & Prob \\
\hline Monday & 0.000936 & 0.000538 & 1.738684 & 0.0822 \\
\hline Tuesday & 0.00032 & 0.000538 & 0.595273 & 0.5517 \\
\hline Wednesday & 0.001266 & 0.000539 & 2.349347 & $\mathbf{0 . 0 1 8 9}$ \\
\hline Thursday & 0.000121 & 0.00054 & 0.223412 & 0.8232 \\
\hline Friday & 0.0000348 & 0.000544 & 0.063947 & 0.949 \\
\hline
\end{tabular}

\begin{tabular}{|c|c|c|c|c|c|c|c|}
\hline & & & & \multicolumn{4}{|c|}{ Heteroskedasticity Test: ARCH LM } \\
\hline & Sensex & BSE 200 & BSE 500 & & Sensex & $\begin{array}{l}\text { BSE } \\
200\end{array}$ & $\begin{array}{l}\text { BSE } \\
500\end{array}$ \\
\hline R-squared & 0.0003 & 0.0007 & 0.0008 & F-statistic & 200.5188 & 362.49 & 399.66 \\
\hline $\begin{array}{l}\text { Durbin-Watson } \\
\text { stat }\end{array}$ & 1.8674 & 1.792359 & 1.7685 & $\begin{array}{l}\text { Obs*R- } \\
\text { squared }\end{array}$ & 191.53 & 334.05 & 365.21 \\
\hline $\begin{array}{l}\text { Q-Stat (P- } \\
\text { Values) }\end{array}$ & $\begin{array}{r}191.71 \\
(0.00)\end{array}$ & $\begin{array}{r}334.35 \\
(0.00)\end{array}$ & $\begin{array}{r}365.55 \\
(0.00) \\
\end{array}$ & $\begin{array}{l}\text { Prob. } \\
F(1,4232)\end{array}$ & 0 & 0 & 0 \\
\hline F-statistic & 11.04037 & 23.976 & 29.593 & $\begin{array}{l}\text { Prob. Chi- } \\
\text { Square(1) }\end{array}$ & 0 & 0 & 0 \\
\hline Prob. $F(2,4228)$ & 0 & 0 & 0 & & & & \\
\hline $\begin{array}{l}\text { Prob. Chi- } \\
\text { Square(2) }\end{array}$ & 0 & 0 & 0 & & & & \\
\hline
\end{tabular}


An analysis of the p-values shows that the Wednesday-Effect is prevalent in all the three indices. Since the coefficient of Monday is not significant in either of the three indices, it can be said that no weekend effect exists. However, the low values of DurbanWatson statistic in the return data indicate autocorrelation in the residuals. The LjungBox Q statistic with the null hypothesis of no serial correlation indicates that an autocorrelation problem of order one exists in the data. This is confirmed by the Breusch-Godfrey Serial Correlation LM Test. Further, as seen by the ARCH LM test with the null hypothesis that no autoregressive conditional heteroskedasticity (ARCH) effect exists, the significant $\mathrm{p}$-values indicate that the return series of the three indices exhibit ARCH effects. As such, the OLS estimation equation is remodelled for autocorrelation of order one by including an AR(1) term on the right side of the dummy regression model and $\mathrm{ARCH}$ effect is taken care of by choosing an appropriate $\mathrm{ARCH}$ family model.

The ARCH model was introduced by Nobel Laureate Engle (1982) to account for volatility clustering, normally found in the financial returns series. Several extensions of the original ARCH model were introduced beginning with the Generalized ARCH (GARCH) model proposed by Bollerslev (1986), Exponential GARCH (EGARCH) model by Nelson (1991), Asymmetric Power ARCH (APARCH) by Ding, Granger and Engle (1993) and others which have been listed in the glossary of Bollersev (2008). These various extensions of ARCH models account for various specific properties of financial data. The selection of the ARCH family model most relevant for the series can be done through the choice of the model with the BIC information criteria that penalise the likelihood. Based on the results provided by these criteria, the EGARCH model has been selected. The EGARCH model as specified by Nelson (1991) accounts for the leverage effect and the asymmetric information property found in financial returns. An EGARCH $(\mathrm{p}, \mathrm{q})$ can be stated as having mean equation of

$r_{t}=\mu+\varepsilon_{t}$ such that $\varepsilon_{t}=\sigma_{t} z_{t}$,

where $z t$ is standard Gaussian constant and the conditional variance equation is given as:

$$
\ln \left(\sigma^{2} t\right)=\omega+\alpha(|z t-1|-\mathrm{E}[|z t-1|])+\gamma z t-1+\beta \ln \left(\sigma^{2} t-1\right)
$$

where

$\omega=$ constant

$\ln \left(\sigma^{2} t-1\right)=$ lag of the conditional variance

$\alpha=$ magnitude effect

$\gamma=$ asymmetric or leverage effect

The model selection and the detailed results are seen in Table 4. After correcting for autocorrelation and $\mathrm{ARCH}$ effects, we find that while no days-of-the-week effect 
14 | MUDRA: Journal of Finance and Accounting, Volume 4, Issue 1, Jan-Jun 2017

exists in the SENSEX index. However, the significant coefficients of Monday and Wednesday in BSE200 and BSE500 indices show that both the weekend effect and the Wednesday effect exist in these two indices.

Table 4: Results of Indices' Returns (corrected for autocorrelation and ARCH effect)

\begin{tabular}{|l|l|l|l|l|l|l|l|}
\hline & ARCH & GARCH & TARCH & EGARCH & APGARCH & $\begin{array}{l}\text { Least } \\
\text { Value of } \\
\text { Schwarz } \\
\text { Criterion }\end{array}$ \\
\hline \multirow{5}{*}{$\begin{array}{l}\text { Schwarz } \\
\text { criterion }\end{array}$} & Sensex & -5.5895 & -5.7794 & -5.79404 & $\mathbf{- 5 . 7 9 3 5 3}$ & -5.794789 & -5.794044 \\
\cline { 2 - 8 } & $\begin{array}{l}\text { BSE } \\
\mathbf{2 0 0}\end{array}$ & -5.5978 & -5.78610 & -5.79625 & $\mathbf{- 5 . 7 9 8 4}$ & -5.796331 & -5.798399 \\
\cline { 2 - 8 } & $\begin{array}{l}\text { BSE } \\
\mathbf{5 0 0}\end{array}$ & -5.6247 & -5.81171 & -5.82144 & $\mathbf{- 5 . 8 2 0 4 0}$ & -5.821697 & -5.820407 \\
\hline
\end{tabular}

\begin{tabular}{|c|c|c|c|c|}
\hline \multicolumn{5}{|c|}{ BSE Sensex } \\
\hline Days & Coefficient & Std. Error & z-Statistic & Prob \\
\hline Monday & 0.000422 & 0.000342 & 1.234889 & 0.2169 \\
\hline Tuesday & $7.73 \mathrm{E}-05$ & 0.000394 & 0.196005 & 0.8446 \\
\hline Wednesday & 0.000747 & 0.000399 & 1.871412 & 0.0613 \\
\hline Thursday & 0.000352 & 0.000378 & 0.930691 & 0.352 \\
\hline Friday & 0.000581 & 0.000365 & 1.593045 & 0.1112 \\
\hline $\mathrm{AR}(1)$ & 0.089216 & 0.015999 & 5.576282 & 0 \\
\hline \multicolumn{5}{|c|}{ Variance equation } \\
\hline $\mathrm{C}(7)$ & -0.430333 & 0.029692 & -14.49307 & 0 \\
\hline $\mathrm{C}(8)$ & 0.21939 & 0.011217 & 19.55858 & 0 \\
\hline $\mathrm{C}(9)$ & -0.090385 & 0.007381 & -12.24557 & 0 \\
\hline $\mathrm{C}(10)$ & 0.96963 & 0.002908 & 333.4844 & 0 \\
\hline \multicolumn{5}{|c|}{ BSE 200} \\
\hline Days & Coefficient & Std. Error & z-Statistic & Prob \\
\hline Monday & 0.000928 & 0.000332 & 2.794499 & 0.0052 \\
\hline Tuesday & 0.000157 & 0.000389 & 0.40408 & 0.6862 \\
\hline Wednesday & 0.000926 & 0.00038 & 2.434707 & 0.0149 \\
\hline Thursday & 0.000539 & 0.000367 & 1.471196 & 0.1412 \\
\hline Friday & 0.000673 & 0.000367 & 1.834697 & 0.0666 \\
\hline \multirow[t]{2}{*}{$\mathrm{AR}(1)$} & 0.127486 & 0.016016 & 7.960081 & 0 \\
\hline & \multicolumn{4}{|c|}{ Variance equation } \\
\hline $\mathrm{C}(7)$ & -0.518428 & 0.034916 & -14.84782 & 0 \\
\hline $\mathrm{C}(8)$ & 0.258529 & 0.013893 & 18.60919 & 0 \\
\hline $\mathrm{C}(9)$ & -0.08626 & 0.007414 & -11.63523 & 0 \\
\hline $\mathrm{C}(10)$ & 0.962842 & 0.003362 & 286.3853 & 0 \\
\hline
\end{tabular}




\begin{tabular}{|l|c|c|c|c|}
\hline & \multicolumn{5}{|c|}{ BSE 500 } \\
\hline \multicolumn{1}{|c|}{ Days } & Coefficient & Std. Error & z-Statistic & Prob \\
\hline Monday & 0.001028 & 0.00033 & 3.120694 & 0.0018 \\
\hline Tuesday & $9.54 \mathrm{E}-05$ & 0.000387 & 0.246688 & 0.8051 \\
\hline Wednesday & 0.000839 & 0.000381 & 2.19923 & 0.0279 \\
\hline Thursday & 0.000559 & 0.000364 & 1.536093 & 0.1245 \\
\hline Friday & 0.000552 & 0.000367 & 1.503414 & 0.1327 \\
\hline AR(1) & 0.136768 & 0.015977 & 8.560311 & 0 \\
\hline & \multicolumn{5}{|c|}{ Variance equation } & 0 \\
\hline C(7) & -0.526161 & 0.03503 & -15.02049 & 0 \\
\hline $\mathrm{C}(8)$ & 0.261101 & 0.014035 & 18.60381 & 0 \\
\hline $\mathrm{C}(9)$ & -0.086682 & 0.007424 & -11.67573 & 0 \\
\hline $\mathrm{C}(10)$ & 0.962226 & 0.003385 & 284.2646 & \\
\hline
\end{tabular}

\begin{tabular}{|c|c|c|c|c|c|c|c|}
\hline & & & & & \multicolumn{3}{|c|}{ Heteroskedasticity Test: ARCH } \\
\hline & Sensex & BSE 200 & $\begin{array}{c}\text { BSE } \\
\mathbf{5 0 0}\end{array}$ & & Sensex & BSE 200 & BSE 500 \\
\hline R-squared & 0.003918 & 0.010393 & 0.01301 & F-statistic & 0.09662 & 0.00362 & 0.00453 \\
\hline $\begin{array}{c}\text { Durbin- } \\
\text { Watson stat }\end{array}$ & 2.040408 & 2.041362 & 2.04279 & & & & \\
\hline $\begin{array}{c}\text { Q-Stat (P- } \\
\text { Values) }\end{array}$ & 1.6109 & $\begin{array}{c}1.2861 \\
(0.204)\end{array}$ & $\begin{array}{c}1.1139 \\
(0.291)\end{array}$ & $\begin{array}{c}\text { Prob. } \\
\text { F(1,4232) }\end{array}$ & 0.7559 & 0.952 & 0.957 \\
\hline $\begin{array}{c}\text { Obs*R- } \\
\text { squared }\end{array}$ & 0.09667 & 0.003628 & $\begin{array}{c}1.37 \mathrm{E}- \\
05\end{array}$ & $\begin{array}{c}\text { Prob. Chi- } \\
\text { Square(1) }\end{array}$ & 0.7559 & 0.952 & $0.957 \mathrm{~s}$ \\
\hline
\end{tabular}

Further as shown by the Q statistics, no serial correlation exists in the residuals. Similarly, as seen by the ARCH LM test, no ARCH effect exists in the residuals. Having seen evidences of seasonality in the daily stock returns, model (4) is used to investigate seasonality in the monthly returns of the three indices. The results of the OLS estimation procedure is shown in Table 5. The results show that while there is no significant monthof-the-year effect in the SENSEX. Yet, the BSE 200 and the BSE 500 indices show a significant December effect i.e. the mean returns in the month of December are significantly different than the mean returns of other months. Further, the Q statistics and the Breusch-Godfrey Serial Correlation LM Test show that there are no patterns in the residuals. The ARCH LM test further confirms that the monthly returns of the three indices do not exhibit autoregressive conditional heteroskedasticity (ARCH) effects.

\subsection{Conclusion}

The efficiency of informational spread and dissemination has been long held as an important and desirable feature of stock markets around the world. The presence of 
16 | MUDRA: Journal of Finance and Accounting, Volume 4, Issue 1, Jan-Jun 2017

seasonality gives rise to investors being able to earn higher returns by timing the investments.

Table 5: Results of OLS Estimation Procedure on Monthly Returns of Three Indices

\begin{tabular}{|c|c|c|c|c|}
\hline \multicolumn{5}{|c|}{ BSE Sensex } \\
\hline Months & Coefficient & Std. Error & t-Statistic & Prob \\
\hline January & -0.002331 & 0.01783 & -0.130726 & 0.8961 \\
\hline February & 0.002427 & 0.017298 & 0.140307 & 0.8886 \\
\hline March & -0.005666 & 0.017298 & -0.327533 & 0.7436 \\
\hline April & 0.002678 & 0.017298 & 0.154799 & 0.8771 \\
\hline May & 0.009507 & 0.017298 & 0.549616 & 0.5832 \\
\hline June & 0.016726 & 0.017298 & 0.966957 & 0.3348 \\
\hline July & 0.015259 & 0.017298 & 0.882119 & 0.3788 \\
\hline August & 0.013714 & 0.017298 & 0.792851 & 0.4288 \\
\hline September & 0.014853 & 0.017298 & 0.85866 & 0.3916 \\
\hline October & -0.003347 & 0.017298 & -0.193502 & 0.8468 \\
\hline November & 0.027408 & 0.017298 & 1.584481 & 0.1147 \\
\hline December & 0.030046 & 0.017298 & 1.736984 & 0.084 \\
\hline \multicolumn{5}{|c|}{ BSE 200} \\
\hline Months & Coefficient & Std. Error & t-Statistic & Prob \\
\hline January & -0.003493 & 0.019765 & -0.176736 & 0.8599 \\
\hline February & 0.005844 & 0.019175 & 0.304755 & 0.7609 \\
\hline March & -0.009127 & 0.019175 & -0.475974 & 0.6346 \\
\hline April & 0.002333 & 0.019175 & 0.121689 & 0.9033 \\
\hline May & 0.013568 & 0.019175 & 0.707585 & 0.4801 \\
\hline June & 0.01047 & 0.019175 & 0.546058 & 0.5857 \\
\hline July & 0.013811 & 0.019175 & 0.720292 & 0.4722 \\
\hline August & 0.019419 & 0.019175 & 1.012761 & 0.3125 \\
\hline September & 0.014038 & 0.019175 & 0.732095 & 0.465 \\
\hline October & -0.004207 & 0.019175 & -0.219428 & 0.8266 \\
\hline November & 0.032972 & 0.019175 & 1.719576 & 0.0871 \\
\hline December & 0.039561 & 0.019175 & 2.0632 & 0.0404 \\
\hline & \multicolumn{4}{|c|}{ BSE 500 } \\
\hline Months & Coefficient & Std. Error & t-Statistic & Prob \\
\hline January & -0.005071 & 0.020137 & -0.251815 & 0.8015 \\
\hline February & 0.004043 & 0.020137 & 0.200769 & 0.8411 \\
\hline March & -0.008979 & 0.019536 & -0.459613 & 0.6463 \\
\hline April & 0.004025 & 0.019536 & 0.206021 & 0.837 \\
\hline May & 0.015012 & 0.019536 & 0.768409 & 0.4432 \\
\hline June & 0.009145 & 0.019536 & 0.468114 & 0.6402 \\
\hline July & 0.013682 & 0.019536 & 0.700323 & 0.4846 \\
\hline
\end{tabular}




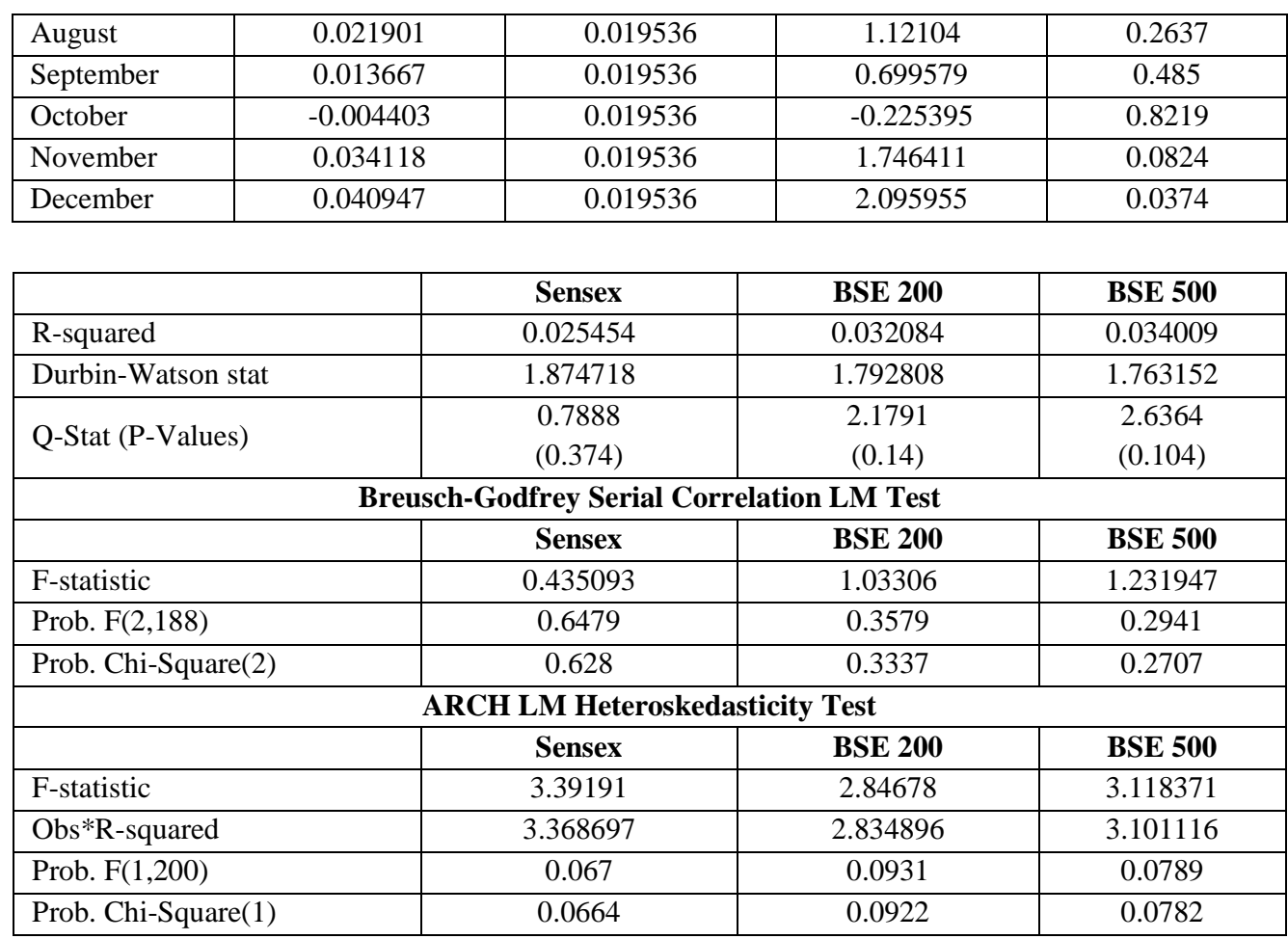

In context of India, the existence of anomalies could be attributable to a number of causes. While the study does not delve into finding these causes, the existence of exploitable patterns in the stock market returns helps active investment strategy to be an important exercise in generating excess returns. As such, the investors can improve their returns by timing their investment in the Indian stock markets. For example, the investor could buy the BSE index fund on Friday (day of the lowest returns) and sell it to Wednesday (day of highest return). Similarly, buy, hold and sell strategy could be adopted to leverage the benefits of the month-of-the-year effect in BSE 200 and BSE 500 stock indices.

\section{References}

Connolly, R. (1989). An examination of the robustness of the weekend effect. Journal of Financial and Quantitative Analysis, 24(2), 133-169.

Connolly, R. (1991). A posterior odds analysis of the weekend effect. Journal of Econometrics, 49, 51-104. 
18 | MUDRA: Journal of Finance and Accounting, Volume 4, Issue 1, Jan-Jun 2017

Borges, M. R. (2009). Calendar effects in stock markets: Critique of previous methodologies and recent evidence in European countries. School of Economics and Management, Technical University of Lisbon, Working Paper no. WP 37/2009/DE/ UECE.

Brown, P. D. (1983). Stock return seasonalities and the tax-loss-selling-hypothesis: Analysis of the arguments and Australian evidence. Journal of Financial Economics, 12, 105-127.

Cross, F. (1973). The behavior of stock prices on Fridays and Mondays. Financial Analysts Journal, 24(6), 67-69.

D, B. (1992). Day of the week patterns of the Indian stock market. Decision, 19(2), 5764.

French K. (1980). Stock returns and the weekend effect. Journal of Financial Economics, 8(1), 55-70.

Gultekin, M. N. (1983). Stock market seasonality: International evidence. Journal of Financial Economics, 12(4), 469-481.

Fama, E.F. (1965). The behavior of stock market prices. Journal of Business, 38(1), 34105.

Fama, E.F. (1970). Efficient capital markets: A review of theory and empirical work. The Journal of Finance, 25(2), 383-417.

Jaffe, J. A. (1985). The week-end effect in stock returns: the international evidence. Journal of Finance, 40(2), 433-454.

Kaur, H. (2004). Time varying volatility in the Indian stock market. Vikalpa, 29(4), 2541.

Patel, N.R. (2012). Day of the week effect in Asian stock markets. Journal of Arts, Science and Commerce, 3(3), 60-10. 
Patel, J. (2008). Calendar effects in the Indian stock market. International Business and Economic Research Journal, 7(3), 61-69.

Purohit, H., \& Tyagi, P. (2015). Calendar effects in stock markets of India and China: An empirical analysis of month-of-the-year-effect. Business Analyst, 36(1), 69-81.

Reinganum, M. (1983). The anomalous stock market behavior of small firms in January empirical test for year-end tax effect. Journal of Financial Economics, 12, 89-104.

Rozeff, M. S. (1976). Capital market seasonality:The case of stock returns. Journal of Financial Economics, 3, 376-402.

Sah, A. N. (2008). Stock Market Seasonality: A Study of the Indian Stock Market. Retrieved from https://www.nseindia.com/content/research/res_paper_final228.pdf

Sarma, S. N. (2004). Stock market seasonality in an emerging market. Vikalpa, 29(3), $35-41$.

Wachtel, S. (1942). Certain observation on seasonal movement in stock prices. Journal of Business, 15, 184-193.

Yakob, N. A. (2005). Seasonality in the Asia Pacific stock markets. Journal of Asset Management, 6(4), 298-318. 